\title{
Province-wide adenovirus type 3 outbreak with severe cases in New Brunswick
}

\author{
Gabriel Girouard MD FRCPC ${ }^{1}$, Richard Garceau MD FRCPC ${ }^{1}$, Louise Thibault MD FRCPC ${ }^{1}$, \\ Christine Bourque $\mathrm{MD}^{2}$, Nathalie Bastien $\mathrm{PhD}^{3}$, Yan $\mathrm{Li} \mathrm{PhD}^{3}$
}

G Girouard, R Garceau, L Thibault, C Bourque, N Bastien, Y Li. Province-wide adenovirus type 3 outbreak with severe cases in New Brunswick. Can J Infect Dis Med Microbiol 2011;22(1):e4e6.

Adenovirus is a commonly isolated virus in clinical samples. Lifethreatening infections, although rare, are described worldwide. An epidemic spread of an adenovirus type 3 strain occurred in the province of New Brunswick during the fall of 2008 to the winter of 2009; it resulted in three severely ill patients, with one fatality. Adenovirus should be considered as a cause of severe community-acquired viral pneumonia, especially when the influenza test is negative.

\section{Éclosion d'adénoviroses de type 3 à l'échelle de la province du Nouveau-Brunswick avec des cas graves}

\begin{abstract}
L'adénovirus est souvent isolé dans les échantillons cliniques. Bien que rares, des adénoviroses fatales sont décrites un peu partout dans le monde. La province du Nouveau-Brunswick a connu une éclosion d'adénoviroses dues à une souche de type 3 entre l'automne 2008 et l'hiver 2009. Chez trois patients, la souche a donné lieu à une infection très grave, dont une fatale. On doit considérer l'adénovirus comme une cause de pneumonie virale extrahospitalière grave, surtout en présence de résultats négatifs au test de dépistage du virus de la grippe.
\end{abstract}

Key Words: Adenovirus; Outbreak; Pneumonia; Type 3

\begin{abstract}
$\mathrm{C}$ urrently, 52 human adenovirus serotypes have been described (1). They are commonly isolated from clinical specimens and often show a seasonal pattern in temperate countries similar to the influenza virus $(2,3)$. Adenoviral infections of the lower respiratory tract are rarely associated with long-term pulmonary aftermaths such as bronchiolitis obliterans and bronchiectasis (4). These viruses can be a threat to severely immunocompromised patients, either by primary infection or endogenous reactivation. In such patients, they often lead to high morbidity and mortality (1). As with many other adenoviruses, the adenovirus type 3 strain has been involved in community and nosocomial outbreaks $(5,6)$. Cases of severe and fatal pneumonia have been related to the adenovirus type 3 strain in both immunocompromised and previously healthy hosts (7-9).
\end{abstract}

\section{CASE PRESENTATION}

A province-wide outbreak of adenovirus type 3 that occurred during a five-month period (fall of 2008 to the winter of 2009) is described. The medical microbiology laboratory of the Centre hospitalier universitaire Dr-Georges-L-Dumont (Moncton, New Brunswick) receives more than 800 specimens annually for respiratory viral cultures. Being the only laboratory offering viral cultures in New Brunswick, the data give important epidemiological information on current viral threats in the community (population estimation of 747,300 individuals). Clinical samples for respiratory viruses are inoculated following the same protocol that has been used in the laboratory since 1993. Briefly, the supernatant from each sample is inoculated in one flat-bottom tube containing in-house prepared Madin-Darby canine kidney cells and human lung adenocarcinoma cells (A549) in buffered minimal essential medium (MP Biomedicals LLC, USA) without fetal bovine serum.

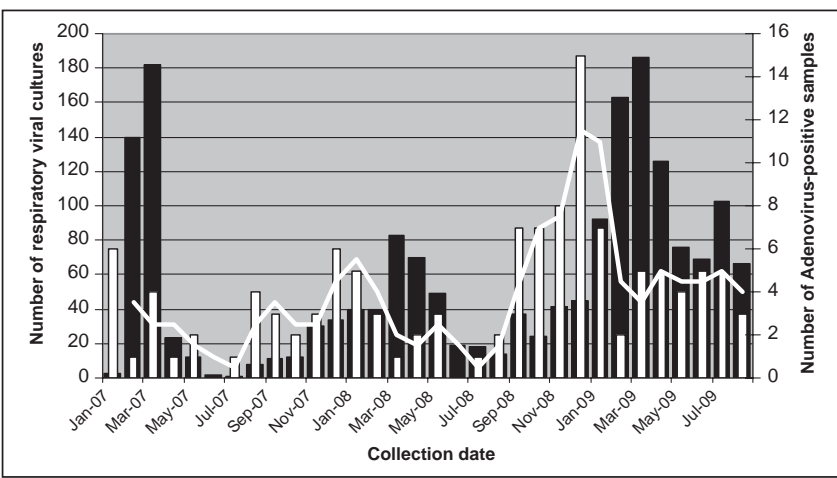

Figure 1) Total number of adenovirus-positive clinical samples (white bars) with moving average (white line) and all respiratory viral cultures (black bars)

Bovine albumin, D-glucose, trypsin, gentamicin, vancomycin and amphotericin $\mathrm{B}$ are added to the tubes, which are centrifuged at $1600 \mathrm{~g}$ for $60 \mathrm{~min}$ at $33^{\circ} \mathrm{C}$ and then held for one week at $33^{\circ} \mathrm{C}$ in $5 \% \mathrm{CO}_{2}$ and observed for a cytopathic effect (CPE). An immunofluorescence assay is performed once the CPE is observed (Light Diagnostics Respiratory Panel I Viral Screening and Identification IFA, Millipore, USA). Samples showing no obvious CPE at the end of the incubation period are also submitted for immunofluorescence testing using the same assay.

During the outbreak period (September 2008 to January 2009), an abrupt rise in the number of adenovirus-positive samples was noted (Figure 1). In total, 42 adenoviruses were isolated (same patient

${ }^{1}$ Département de microbiologie et des maladies infectieuses, Centre hospitalier universitaire Dr-Georges-L-Dumont, Moncton, Nouveau-Brunswick; ${ }^{2}$ Département de microbiologie et d'infectiologie, Faculté de médecine et des sciences de la santé, Université de Sherbrooke, Sherbrooke, Québec;

${ }^{3}$ Laboratoire national de microbiologie, Agence de la santé publique du Canada, Winnipeg, Manitoba

Correspondence and reprints: Dr Gabriel Girouard, Département de microbiologie et des maladies infectieuses, Centre hospitalier universitaire Dr-Georges-L-Dumont, 330 avenue Université, Moncton, Nouveau-Brunswick E1C 2Z3. Telephone 506-862-4140, fax 506-862-4827, e-mail gabriel.girouard@vitalitenb.ca 
TABLE 1

Laboratory data of a patient with fatal adenovirus type 3 pneumonia

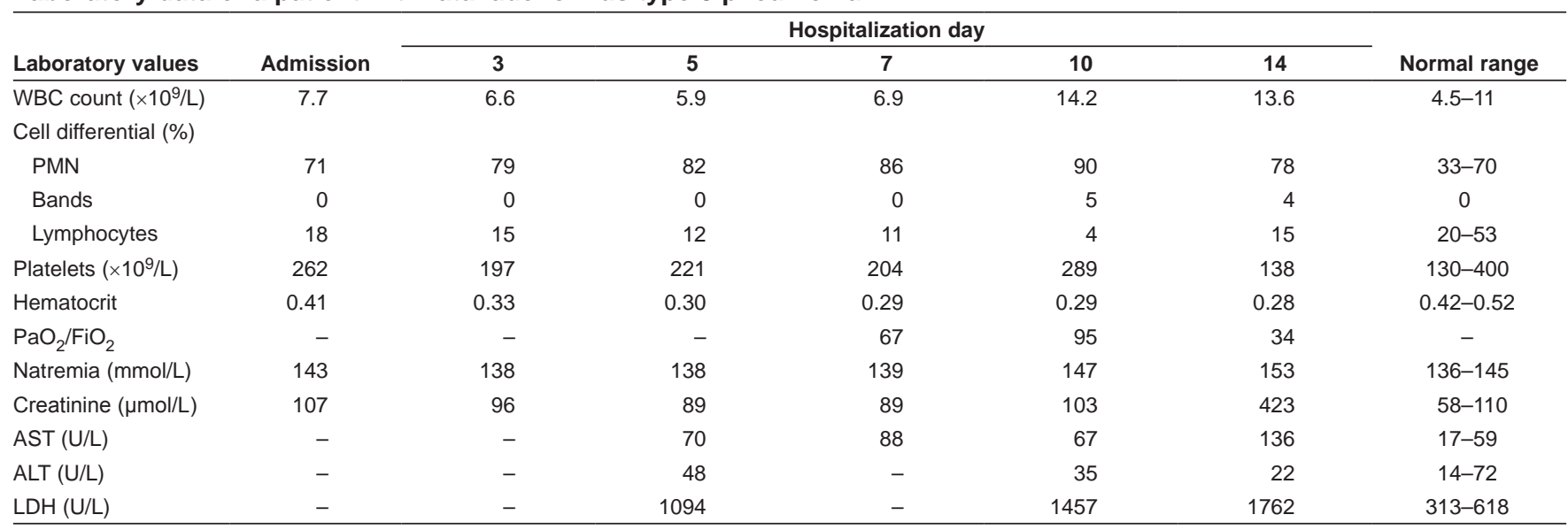

ALT Alanine aminotransferase; AST Aspartate aminotransferase; FiO $_{2}$ Fraction of inspired oxygen; LDH Lactate dehydrogenase; $\mathrm{PaO}{ }_{2}$ Arterial oxygen tension;

PMN Polymorphonuclear; WBC White blood cell

cultures excluded). The sources of the specimens were the following: $43 \%$ nasopharyngeal, $24 \%$ unspecified, $22 \%$ stool, $7 \%$ ocular, $2 \%$ urine and $2 \%$ bronchial. Adenoviruses were isolated in $15 \%$ of the total respiratory viral cultures requested during that period. Cases were distributed in the province according to the federal electoral districts: Acadie-Bathurst (two cases), Beauséjour (two cases), Fredericton (two cases), Fundy-Royal (no cases), Madawaska-Restigouche (one case), Miramichi (no cases), Moncton-Riverview-Dieppe (31 cases), Saint-John (four cases), South-West (no cases) and Tobique-Mactaquac (no cases). Age group distribution was as follows: five years or younger ( 22 cases), six to 12 years (10 cases), 13 to 18 years (no cases), and 19 years or older ( 10 cases). The majority of patients were female (60\%). The provincial Communicable Disease Control Unit was notified and a province-wide notice was rapidly broadcasted. Seventeen viral strains were sent to the National Microbiology Laboratory in Winnipeg, Manitoba, for partial hexon gene sequencing, as previously described (10); sequencing showed that they all belonged to the adenovirus type 3 strain.

During this outbreak, and to the authors' best knowledge, three cases of severe adenovirus pneumonia were reported (individuals between 33 and 40 years of age, all immunocompetent male patients, and all hospitalized). Two were confirmed by positive culture. The third patient seroconverted toward adenovirus (fourfold increment in complement fixation titre); the throat viral culture was negative. Of these three cases, one was fatal. A 40-year-old man was admitted to the Centre hospitalier universitaire Dr-Georges-LDumont on January 2, 2009, and initially presented with a flu-like illness, shaking chills, shortness of breath and productive cough. He was known to be epileptic and to have sleep apnea, for which he underwent a uvuloplasty. Table 1 shows the patient's paraclinical data during hospitalization. An initial chest x-ray showed ill-defined bilateral lower lobe infiltrations that progressed rapidly toward a frank right lower lobe consolidation on day 3. He was initially treated for community-acquired pneumonia with antibiotics (cefuroxime and moxifloxacin). Bronchoscopy was performed on day 6. Bronchial washing and tracheal aspirate cultures performed while he was on antibiotics showed normal oropharyngeal flora; polymerase chain reaction for influenza, Legionella urinary antigen test and cold agglutinins blood test were negative. On day 8 , his condition suddenly deteriorated and he was intubated. Chest computed tomodensitometry revealed bilateral patchy ground-glass opacifications and consolidation of both lower lobes with pleural effusions. On the ninth day of hospitalization, $72 \mathrm{~h}$ viral cultures from the bronchial washing showed a typical adenovirus CPE on A549 cells, which was confirmed by indirect immunofluorescence assay. Cidofovir $(1 \mathrm{mg} / \mathrm{kg})$ with probenecid was started immediately. He received a second dose of cidofovir $(3 \mathrm{mg} / \mathrm{kg})$ with probenecid on day 11 . He also received $400 \mathrm{mg} / \mathrm{kg}$ of intravenous pooled gammaglobulins (Gammagard liquid, Baxter Healthcare Corporation). His condition improved transitorily. He remained febrile throughout his hospitalization, with spiking fevers above $39^{\circ} \mathrm{C}$. His health rapidly declined five days after starting cidofovir with multiple organ failure and intractable acute respiratory distress syndrome leading to death. Sera collected on day 6 and day 12 showed seroconversion toward adenovirus with an acute serum titre of 1:64 and a late serum titre higher than 1:256 (complement fixation). An autopsy was not performed, as requested by his family.

\section{DISCUSSION}

The described outbreak and present case report illustrates some important issues concerning adenovirus pneumonia. First, the adenovirus type 3 strain is one of the most prevalent types of adenovirus strains detected globally (11). The adenovirus type 3 strain seems to be the predominant virus serotype isolated in Canada ( $\mathrm{Y} \mathrm{Li}$, personal communication). At the onset of this outbreak and because of the severity of the three cases reported here, a recently described highly virulent and pneumotropic adenovirus type 14 strain was first suspected $(12,13)$. Partial hexon gene sequencing revealed it to be the adenovirus type 3 strain. This province-wide outbreak may reflect recently observed outbreaks related to the adenovirus type 3 strain, in which a new virulent subgenomic variant (adenovirus type 3 a50 strain) was described $(9,11)$. Adenovirus spreads rapidly in a community, with higher attack rates related to crowding of susceptible hosts (14). This experience shows an epidemic spread of an adenoviral strain that swept the province during a very short period. One patient who initially presented with community-acquired pneumonia had a fatal outcome, despite treatment aimed at the adenovirus. Barring that no autopsy was performed to definitely prove adenovirus pneumonia as the cause of death, the adenovirus type 3 strain was the sole pathogen isolated in this patient who subsequently seroconverted. Heightened clinical suspicion is important once an adenovirus outbreak is known to occur. Conjunctivitis, high fever with shaking chills, lobar pneumonia not responding to antibiotics or rapidly progressing, leukocytosis, hypoxemia and multiple organ failure are many elements that can suggest adenovirus pneumonia. Without viral respiratory culture or targeted/multiplex polymerase chain reaction, this case would have been missed. Severe cases often show an unpredictable and rapidly downhill deterioration toward death despite aggressive treatment, 
sometimes following a transient improvement as demonstrated in our case. Specific treatment aimed at adenovirus is still limited to cidofovir and pooled gammaglobulins. Clinicians must keep in mind other potential causes of viral pneumonia in severely ill patients, especially when influenza testing is negative, because this can change management and treatment.

\section{REFERENCES}

1. Echavarria M. Adenovirus in immunocompromised hosts. Clin Microbiol Rev 2008;21:704-15.

2. Robinson C, Echavarria M. Adenoviruses. In: Murray PR, Baron EJ, Jorgensen JH, Landry ML, Pfaller MA, eds. Manuel of Clinical Microbiology. Washington: ASM Press, 2007:1589-600.

3. Ruuskanien O, Meurman O, Akusjarvi G. Adenoviruses. In: Richman DD, Whitley RJ, Hayden F, eds. Clinical Virology. Washington: ASM Press, 2002:515-35.

4. Hayashi S, Hogg JC. Adenovirus infections and lung disease. Curr Opin Pharmacol 2007;7:237-43.

5. Chang SY, Lee CN, Lin PH, et al. A community-derived outbreak of adenovirus type 3 in children in Taiwan between 2004 and 2005. J Med Virol 2008;80:102-12.

6. James L, Vernon MO, Jones RC, et al. Outbreak of human adenovirus type 3 infection in a pediatric long-term care facility - Illinois, 2005. Clin Infect Dis 2007;15:416-20.

7. Regagnon C, Souweine B, Archimbaud C, Duperron F, Thouvenot D, Peigue-Lafeuille $\mathrm{H}$. A fatal case of adenovirus type 3 pneumonia in an immunocompetent adult. Med Mal Infect 2004;34:102-4.

8. Barker JH, Luby JP, Dalley AS, Bartek WM, Burns DK, Erdman DD. Fatal type 3 adenoviral pneumonia in immunocompetent adult identical twins. Clin Infect Dis 2003;37:142-6.

9. Landry ML, Lebeck MG, Capuano AW, McCarthy T, Gray GC. Adenovirus type 3 outbreak in Connecticut associated with a novel variant. J Med Virol 2009;81:1380-4.

10. Lu X, Erdman DD. Molecular typing of human adenoviruses by PCR and sequencing of a partial region of the hexon gene. Arch Virol 2006;151:1587-602.

11. Lebeck MG, McCarthy TA, Capuano AW. Emergent US adenovirus 3 strains associated with an epidemic and serious disease. J Clin Virol 2009;46:331-6.

12. Louie JK, Kajon AE, Holodniy M. Severe pneumonia due to adenovirus serotype 14: A new respiratory threat? Clin Infect Dis 2008;46:421-5.

13. Lewis PF, Schmidt MA, Lu X, et al. A community-based outbreak of severe respiratory illness caused by human adenovirus serotype 14 . J Infect Dis 2009;199:1427-34.

14. Baum SG. Adenovirus. In: Mandell GL, Bennett JE, Dolin R, eds. Principals and Practice of Infectious Diseases. Elsevier Inc, 2005:1835-41. 


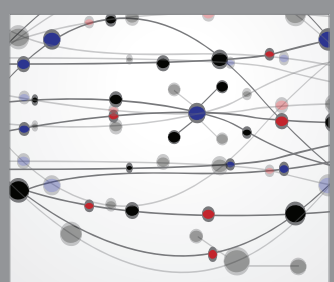

The Scientific World Journal
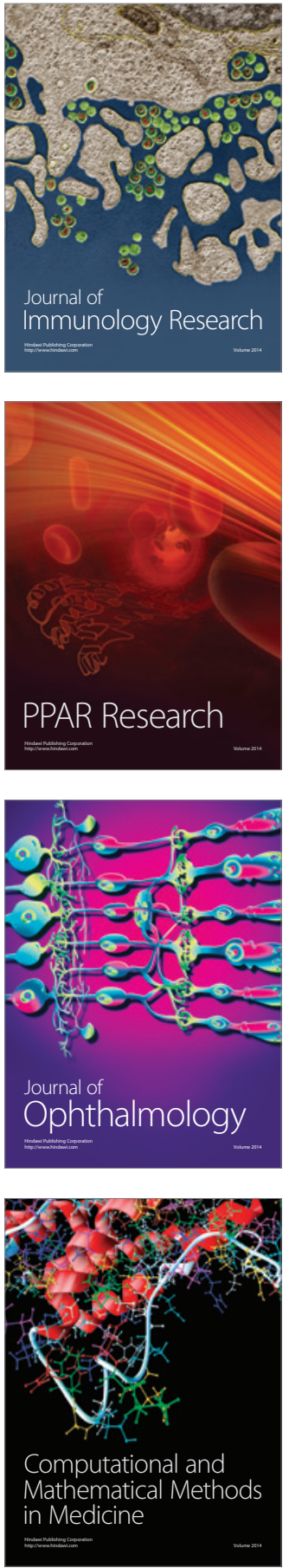

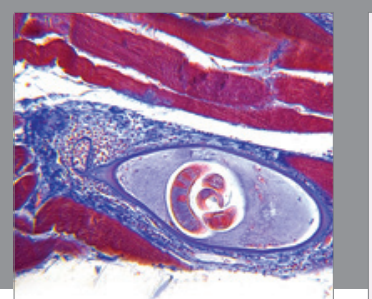

Gastroenterology Research and Practice

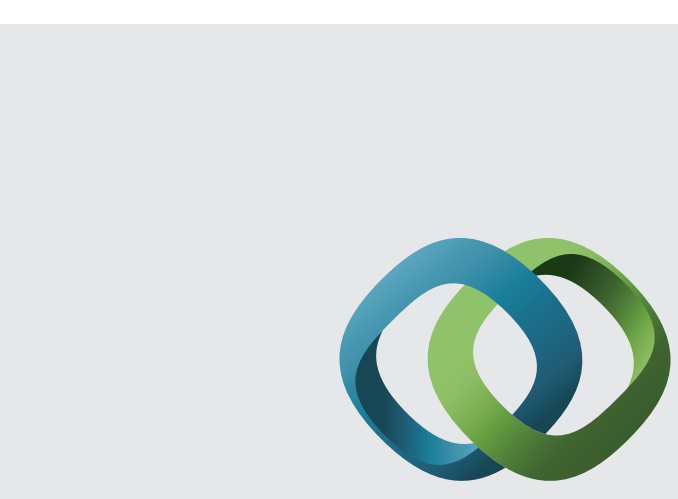

\section{Hindawi}

Submit your manuscripts at

http://www.hindawi.com
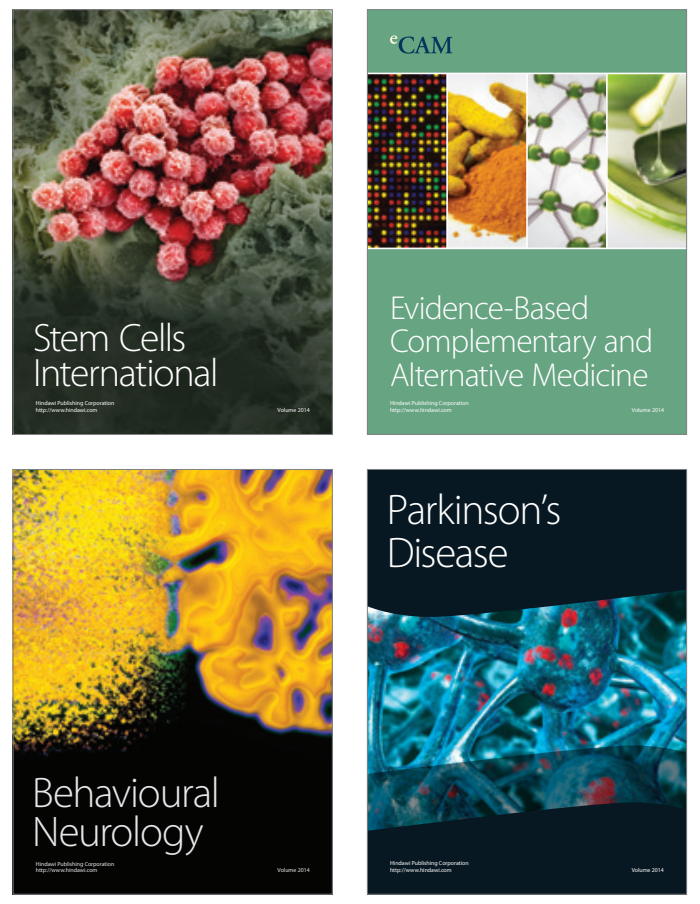
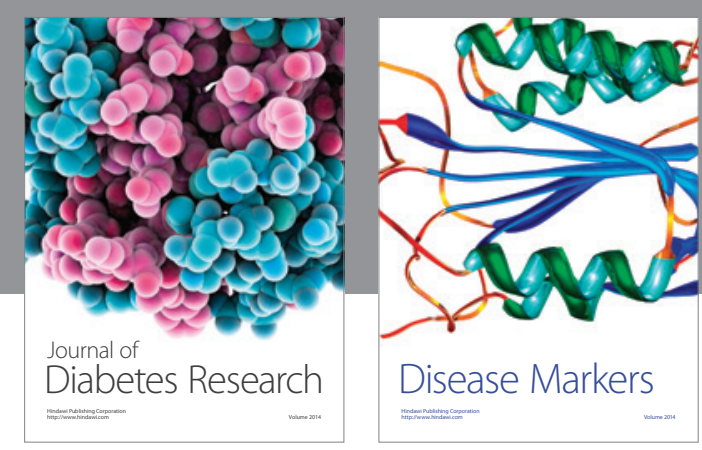

Disease Markers
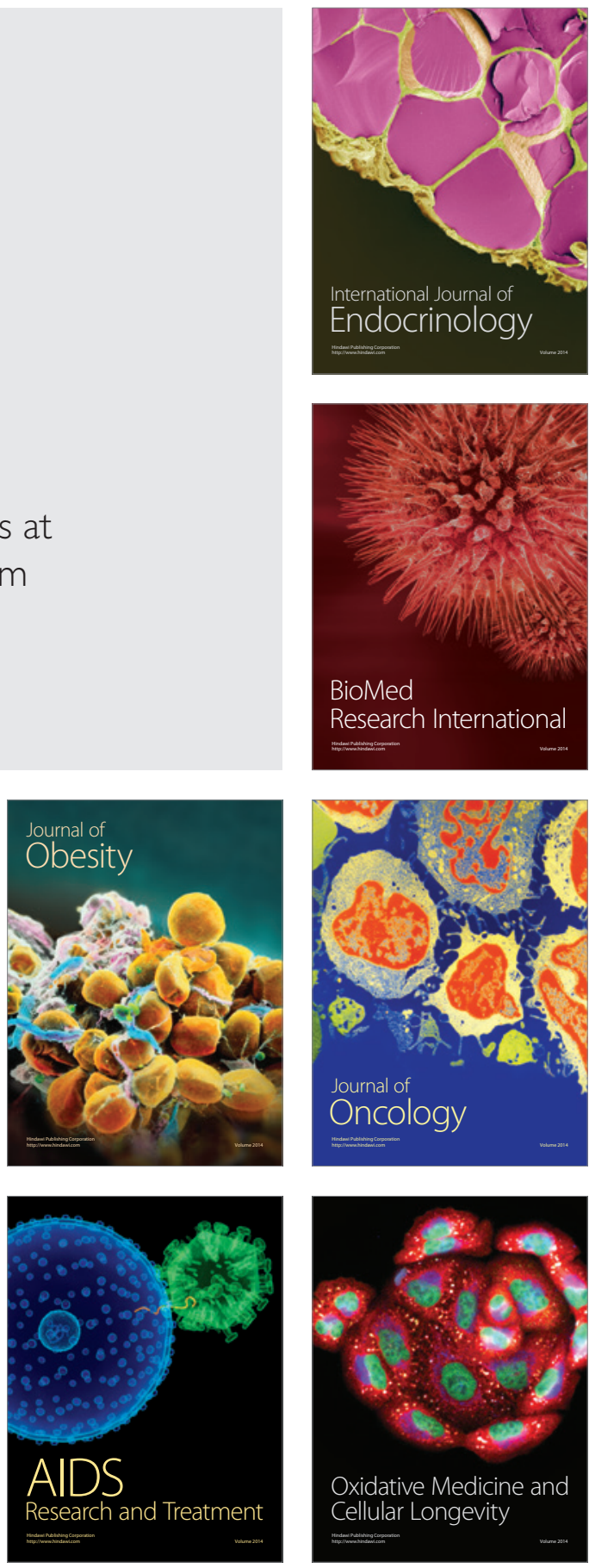